\title{
Genetic evaluations of Chinese patients with odontohypophosphatasia resulting from heterozygosity for mutations in the tissue-non- specific alkaline phosphatase gene
}

\author{
Jia Wan ${ }^{1, *}$, Li Zhang ${ }^{2, *}$, Tang Liu ${ }^{1}$ and Yewei Wang ${ }^{3}$ \\ ${ }^{1}$ Department of Orthopaedics, The Second Xiangya Hospital of Central South University, Changsha 410011, P.R.China \\ ${ }^{2}$ Department of Endocrinology, The Fifth Central Hospital of Tianjin, Tianjin 300192, P.R.China \\ ${ }^{3}$ Department of Hemotology, The Second Xiangya Hospital of Central South University, Changsha 410011, P.R.China \\ *Jia Wan and Li Zhang are the co-first authors \\ Correspondence to: Tang Liu, email: liutang1204@csu.edu.cn \\ Yewei Wang, email: wangyeweixy@hotmail.com \\ Keywords: hypophosphatasia, odonto-hypophosphatasia, gene mutation, premature exfoliation of primary teeth, TNSALP \\ Received: January 24, $2017 \quad$ Accepted: May 07, $2017 \quad$ Published: May 23, 2017 \\ Copyright: Wan et al. This is an open-access article distributed under the terms of the Creative Commons Attribution License 3.0 \\ (CC BY 3.0), which permits unrestricted use, distribution, and reproduction in any medium, provided the original author and source \\ are credited.
}

\section{ABSTRACT}

Background: Hypophosphatasia is a rare heritable metabolic disorder characterized by defective bone and tooth mineralization accompanied by a deficiency of tissue-non-specific (liver/bone/kidney) isoenzyme of alkaline phosphatase activity, caused by a number of loss-of-function mutations in the alkaline phosphatase liver type gene. We seek to explore the clinical manifestations and identify the mutations associated with the disease in a Chinese odonto- hypophosphatasia family.

Results: The proband and his younger brother affected with premature loss of primary teeth at their 2-year-old. They have mild abnormal serum alkaline phosphatase and 25-hydroxy vitamin D values, but the serum alkaline phosphatase activity of their father, mother and grandmother, who showed no clinical symptoms of hypophosphatasia, was exhibited significant decreased. In addition to premature loss of primary teeth, the proband and his younger brother showed low bone mineral density, X-rays showed that they had slight metaphyseal osteoporosis changes, but no additional skeletal abnormalities. Deoxyribonucleic acid sequencing and analysis revealed a single nucleotide polymorphism c.787T >C (p.Y263H) in exon 7 and/or a novel mutation $c_{\text {. }}-92 \mathrm{C}>\mathrm{T}$ located at 5'UTR were found in the affected individuals.

Materials and Methods: We examined all individuals of an odontohypophosphatasia family by clinical and radiographic examinations as well as laboratory assays. Furthermore, all 12 exons and the exon-intron boundaries of the alkaline phosphatase liver type gene were amplified and directly sequenced for further analysis and screened for mutations.

Conclusion: Our present findings suggest the single nucleotide polymorphism c.787T $>C$ and C.-92C $>$ T should be responsible for the odonto- hypophosphatasia disorders in this family.

\section{INTRODUCTION}

Hypophosphatasia (HPP) is a rare inherited metabolic disease characterized by defective bone and tooth mineralization and a deficiency of tissue-non- specific (liver/bone/kidney) isoenzyme of alkaline phosphatase (TNSALP) activity. The disease is caused by mutations in the alkaline phosphatase liver type (ALPL) gene [1]. The symptoms of this disease are vary widely in clinical manifestation, which spans from stillbirth without 
skeletal mineralization in utero or at birth to premature loss of teeth without bone symptoms occuring among childhood or adult life [2]. Six clinical categories of HPP have been classified according to the age at diagnosis and the severity of the symptoms: lethal perinatal, benign perinatal, infantile, childhood, adult, and odontohypophosphatasia (odonto-HPP) forms $[3,4]$. The ALPL gene, localized on chromosome 1p36.1-34, comprises of 12 exons scattered over 50 kilobases $[5,6]$. Thus far, at least 335 mutations are known and reported in the tissue nonspecific alkaline phosphatase gene mutations database (ALPL gene mutation database). TNSALP hydrolyzes mineralization inhibitor, inorganic pyrophosphate (PPi), and provides inorganic phosphate $(\mathrm{Pi})$ to promote the process of mineralization. When TNSALP activity is reduced or lost, extracellular PPi accumulates and inhibits the formation of hydroxyapatite $[7,8]$. Consequently, the inhibition of hydroxyapatite formation leads to deficient mineralization of bones and teeth accompanied by highly variable clinical manifestations (Figure 1) [9].

Odonto-HPP is the least severe of HPP characterized by premature exfoliation of primary teeth and/or severe dental caries as an isolated finding without additional abnormalities of the skeletal system or as part of the other forms of HPP [10-12]. Dental X-rays shows reduced alveolar bone, enlarged pulp chambers and root canals [11]. Biochemical findings are essentially indistinguishable from those of patients with mild forms of childhood or adult HPP [2].

We report two brothers with premature exfoliation of primary teeth as their only clinical manifestation of HPP.

\section{RESULTS}

\section{Clinical examination}

Panoramic radiographs of the proband demonstrated that the erupted teeth were normal and the radiographs of the younger brother showed reduced alveolar bone, enlarged pulp chambers, and abnormal morphology of the unerupted permanent molars. X-ray of knee joints presented metaphyseal osteoporosis changes in femurs and tibiae (Figures 2 and 3). Ultrasonographic assessment of BMD in distal radius and middle tibia showed low bone mineral density for the proband and his younger brother. In addition, their levels of serum ALP moderately decreased, whose values were $41.5 \mathrm{U} / \mathrm{L}$ and $43.4 \mathrm{U} / \mathrm{L}$, respectively (regular scope for children 110-550 U/L). No aberrant variation in serum $\mathrm{Ca}, \mathrm{PTH}, \mathrm{ESR}$ and microelement were detected. But a high level of serum $\mathrm{P}$ (2.08 $\mathrm{mmol} / \mathrm{L}$ and $1.97 \mathrm{mmol} / \mathrm{L}$, respectively, normal range for children $0.90-1.34 \mathrm{mmol} / \mathrm{L})$ and low serum 25-hydroxy vitamin D (50.40 nmol/L and $55.70 \mathrm{nmol} / \mathrm{L}$, respectively, normal range for children $75-175 \mathrm{mmol} / \mathrm{L}$ ) were observed.
The serum alkaline phosphatase (ALP) levels of the father, mother and grandmother were below normal, which is $25.4 \mathrm{U} / \mathrm{L}, 41.9 \mathrm{U} / \mathrm{L}$ and $25 \mathrm{U} / \mathrm{L}$, respectively (normal range for adult men 62-176 U/L, adult women 55$147 \mathrm{U} / \mathrm{L})$. Their serum electrolyte level was normal, but serum 25-hydroxy vitamin D level was slightly decreased. However, they all had no history of precocious absent of primary teeth and bone diseases. The other individual of the proband's family (grandfather) was healthy, and neither clinical signs nor laboratory assays detected any abnormal (Table 1).

\section{Mutation analyses}

Pedigree data and mutation analysis results are shown in Figure 4. Screening for mutations in the ALPL gene disclosed five hereditary change in the brothers. Firstly, there was a heterozygous substitution $\mathrm{T}$ to $\mathrm{C}$ at nucleotide position 787 (c.787T $>$ C) in exon 7, it leads to a tyrosine to histidine substitution at the 263th amino acid (p.Y263H). The second and third alterations identified in the brothers were mutations in the 5' untranslated region (5'-UTR) c.-92C $>\mathrm{T}$ and 3' untranslated region (3'UTR) c.1701A $>$ G. The fourth and fifth were nonsense mutations, located in exon $5($ c.330T $>$ C) and exon 9 (c.876A $>\mathrm{G})$, respectively. Other family members were also analyzed the ALPL genes, and the results showed that all four adults were carriers of genetic alterations [the father: c.787T $>$ C (p.Y263H), c.T330T $>$ C (non-sense), c.876A $>$ G (non-sense) and 3'UTR (c.1701A >G), the mother: 5'UTR (c.-92C $>$ T), c.787T $>$ C (p.Y263H) and c.876A $>$ G (nonsense), the grandfather: c.330T $>\mathrm{C}$ (non-sense) and 3'UTR (c.1701A $>$ G), the grandmother: c.787T $>$ C (p.Y263H) and c. $876 \mathrm{~A}>\mathrm{G}$ (non-sense)]. Of the five mutations identified, 4 are single nucleotide polymorphisms (SNPs). These SNPs were: c. $330>$ TC, c. $1701 \mathrm{~A}>\mathrm{G}, \mathrm{c} .876 \mathrm{~A}>\mathrm{G}$ and c. $1701 \mathrm{~A}>\mathrm{G}$. Only the mutation of c.-92C $>$ T located at 5'UTR is absent from the SNP database and the ALPL gene mutation database, thus, these patients (the two brothers and their mother) carry a new missense mutation in the ALPL gene. In addition, the SNP c.787T $>\mathrm{C}(\mathrm{p} . \mathrm{Y} 263 \mathrm{H})$ was present in a heterozygous state, and this mutation was detected in the family members exhibiting a decrease in serum ALP levels, which confirmed that the sequence aberration is closely related to the serum ALP disorders in this family (Table 2 and Figure 5).

\section{DISCUSSION}

HPP is a rare hereditary disorder of bone and teeth metabolism caused by loss of function within ALPL gene encoding TNSALP [1]. Human TNSALP protein is a chain of 524 amino acid residues, HPP derived from any mutation in the ALPL gene resulting in a decrease in the efficient activity of TNSALP and leading to extracellular accumulation of PPi, a TNSALP substrate and potent 
inhibitor of mineralization [13, 14]. The high clinical variability of the HPP is associated with considerable large number of allelic heterogeneity of the ALPL gene. To date, 335 mutations have been found in the ALPL gene, which are associated with HPP. About 71.6\% of the known mutations are missense mutations, and the remaining including small deletions accounted for $11.0 \%$, splicing mutations accounted for $6.0 \%$, nonsense mutations accounted for $4.8 \%$, small insertions accounted for $3.0 \%$, large deletions accounted for $2.7 \%$, insertions or deletions accounted for $0.96 \%$ and and regulatory sequence mutations accounted for $0.3 \%$.

Odonto-HPP refers to dental manifestations alone occurring in HPP, usually independent of the additional abnormalities of the skeletal system [15]. The odontoHPP, due to the mild of symptoms or as part of the other forms of HPP, is not well documented. Only a few mutations responsible for odonto-HPP have been published compared to other forms of HPP. In the present study, our sequencing analysis results showed that a heterozygous $\mathrm{T}$ to $\mathrm{C}$ transition at c.787 in exon 7, which leading to a tyrosine to histidine substitution at position 263 in the affected members. The unaffected members of the analyzed family did not carry the same mutation. The ALPL gene mutation database also did not contain the mutation information, but this mutation can find in the SNP database. These findings altogether support that the c.787T $>\mathrm{C}(\mathrm{p} . \mathrm{Y} 263 \mathrm{H})$ is a pathogenic mutation in the ALPL gene. Therefore, we believe that the SNP $(\mathrm{c} .787 \mathrm{~T}>\mathrm{C})$ is the cause of the serum ALP disorders in this family. Furthermore, the SNP c.787T $>$ C that a tyrosine to histidine substitution at position 263 was previously shown to decrease the bone mineral density (BMD) and catalytic property of TNSALP in postmenopausal Japanese women, in which the $K \mathrm{~m}$ value was decreased significantly. [16, 17]. However, another study in favor of the sequence variation in linkage disequilibrium (LD) with haplotype E have an aggravating factor resulting in loss of haplosufficiency in European ancestry HPP patients, rather than supporting the role of c.787T $>C$ polymorphism itself [18]. The TNSALP protein is a homodimeric phosphomonoesterase linked to the plasma membrane via

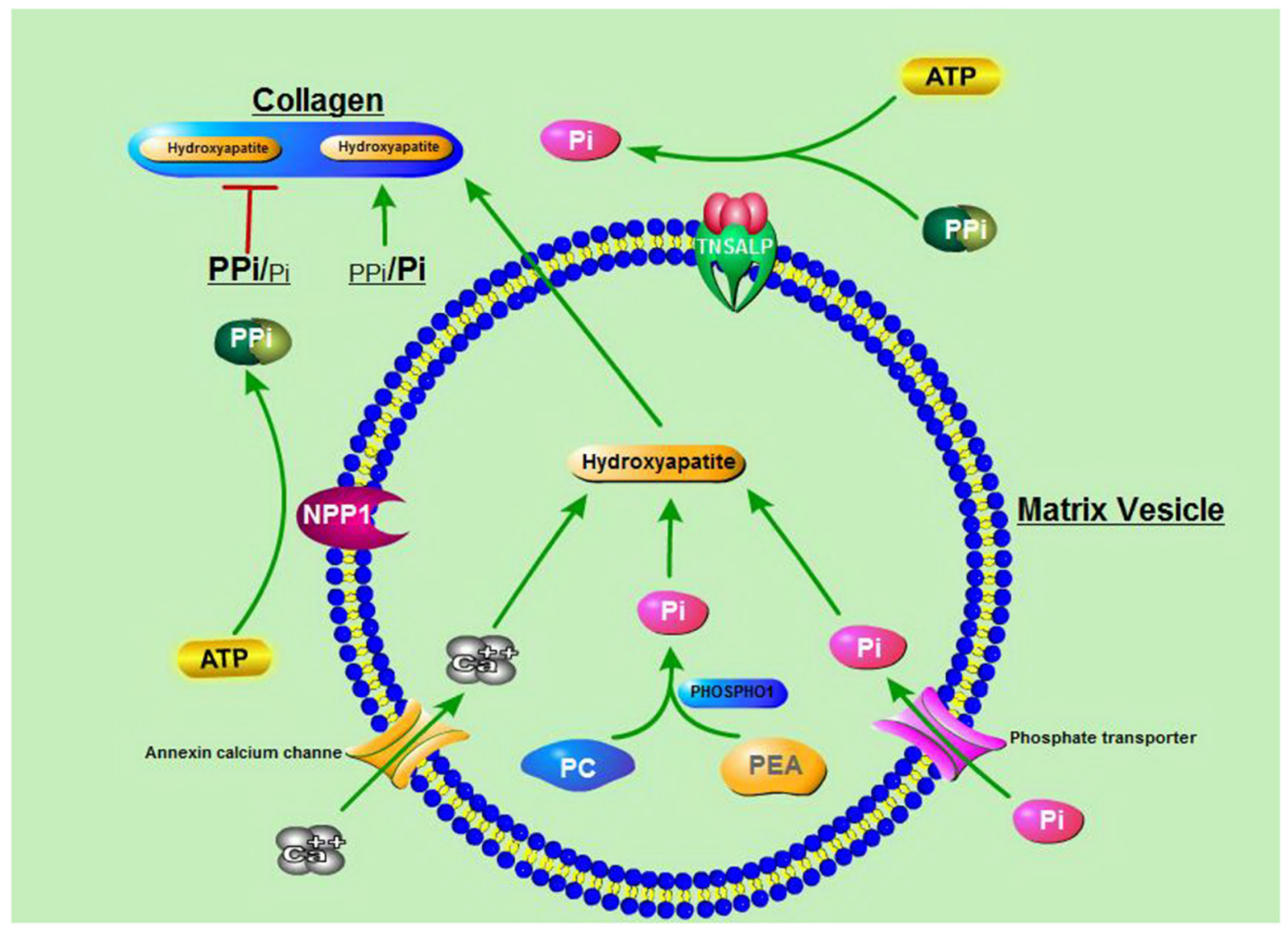

Figure 1: Schematic illustration of the process of mineralization. Mineralization begins with hydroxyapatite formation in the matrix vesicles budding from hypertrophic chondrocytes and osteoblasts. Hydroxyapatite is formed from $\mathrm{Ca}^{2+}$ incorporated by the annexin calcium channel and from Pi. The source of Pi involves two independent biochemical pathways: intravesicular Pi generation by the enzymatic action of PHOSPHO1 and influx of Pi, generated in the perivesicular space by the activities of TNAP and NPP1, via phosphate transporter. PPi which inhibits hydroxyapatite formation, is hydrolyzed by TNAP. The balance between the PPi and Pi is crucial for the mineralization.

PC: phosphocholine; PEA: phosphoethanolamine; Pi: inorganic phosphate; PPi: inorganic pyrophosphate. 

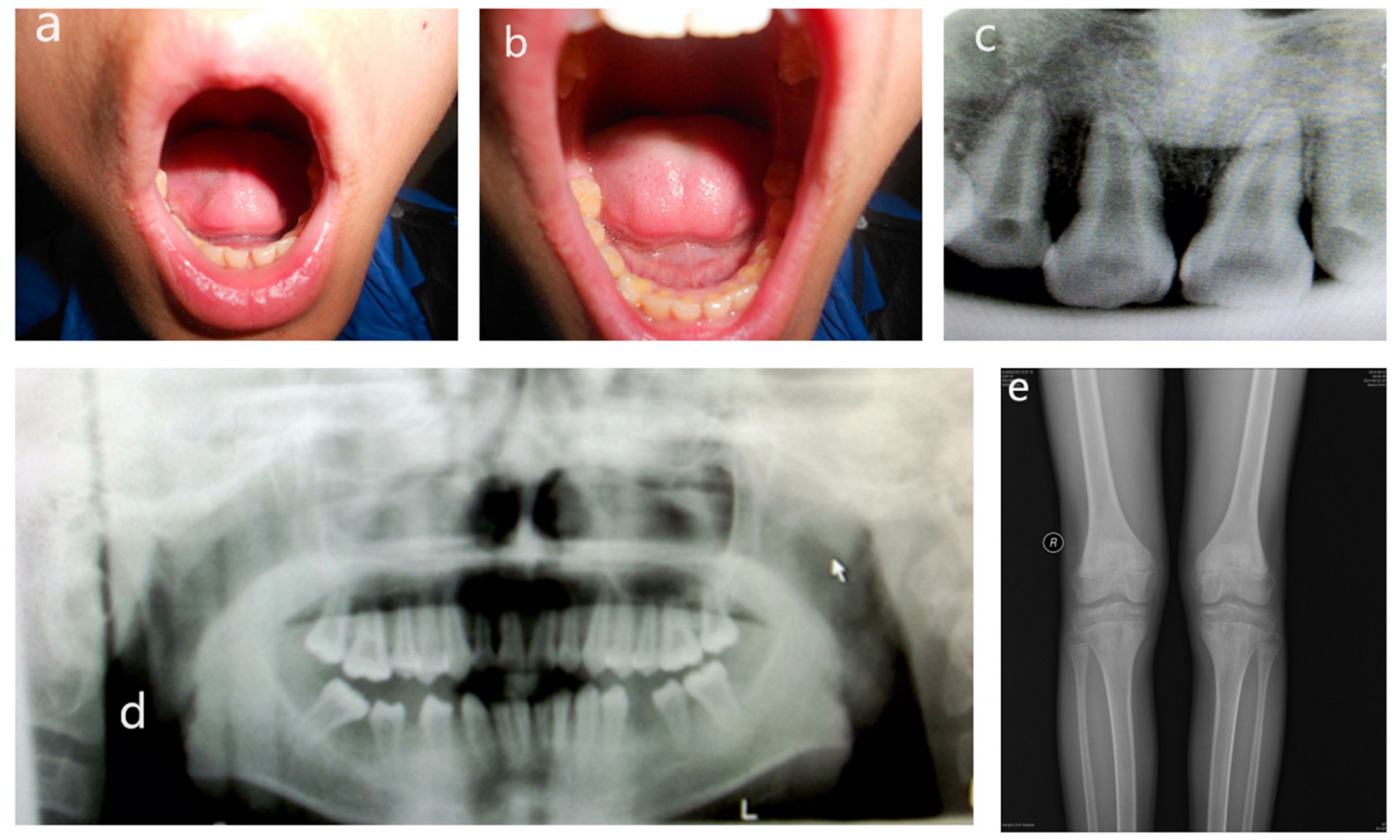

Figure 2: Clinical features of proband. (A, B) Intra-oral photograph of proband showing that permanent teeth were erupted. (C, D) Panoramic radiographs showing normal permanent teeth. (E) Plain films of a knee joint presenting with metaphyseal osteoporosis changes.
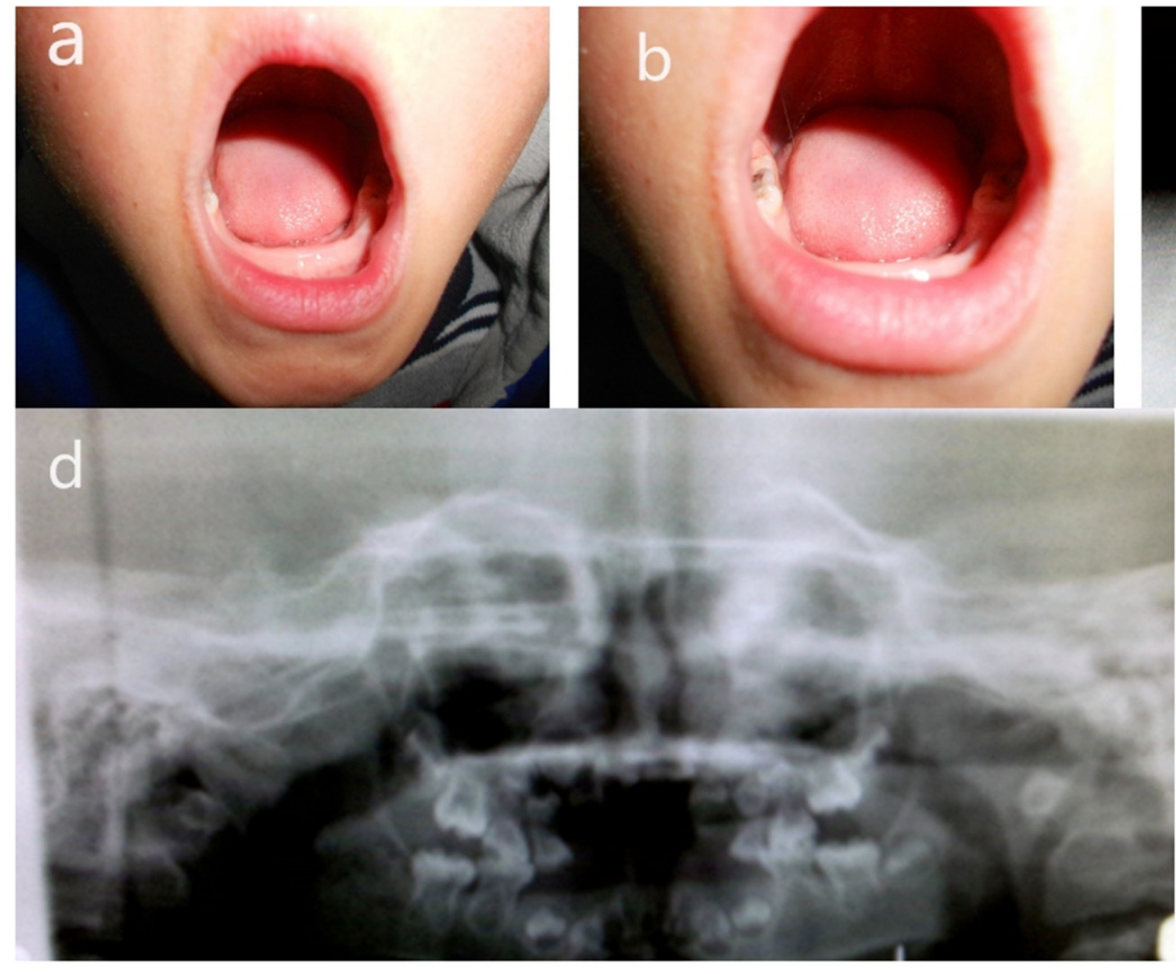
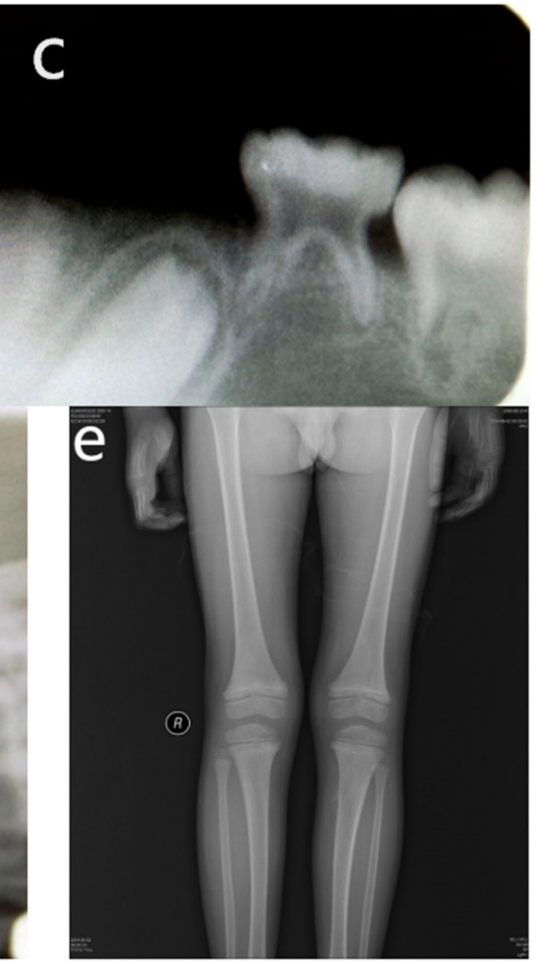

Figure 3: Clinical features of younger brother. (A, B) Intra-oral photograph of proband showing premature exfoliation of primary teeth. (C, D) Panoramic radiographs showing reduced alveolar bone, enlarged pulp chambers, and abnormal morphology of the unerupted permanent molars. (E) Plain films of a knee joint presenting with metaphyseal osteoporosis changes. 
Table 1: Clinical Characteristics of the pedigree in this study

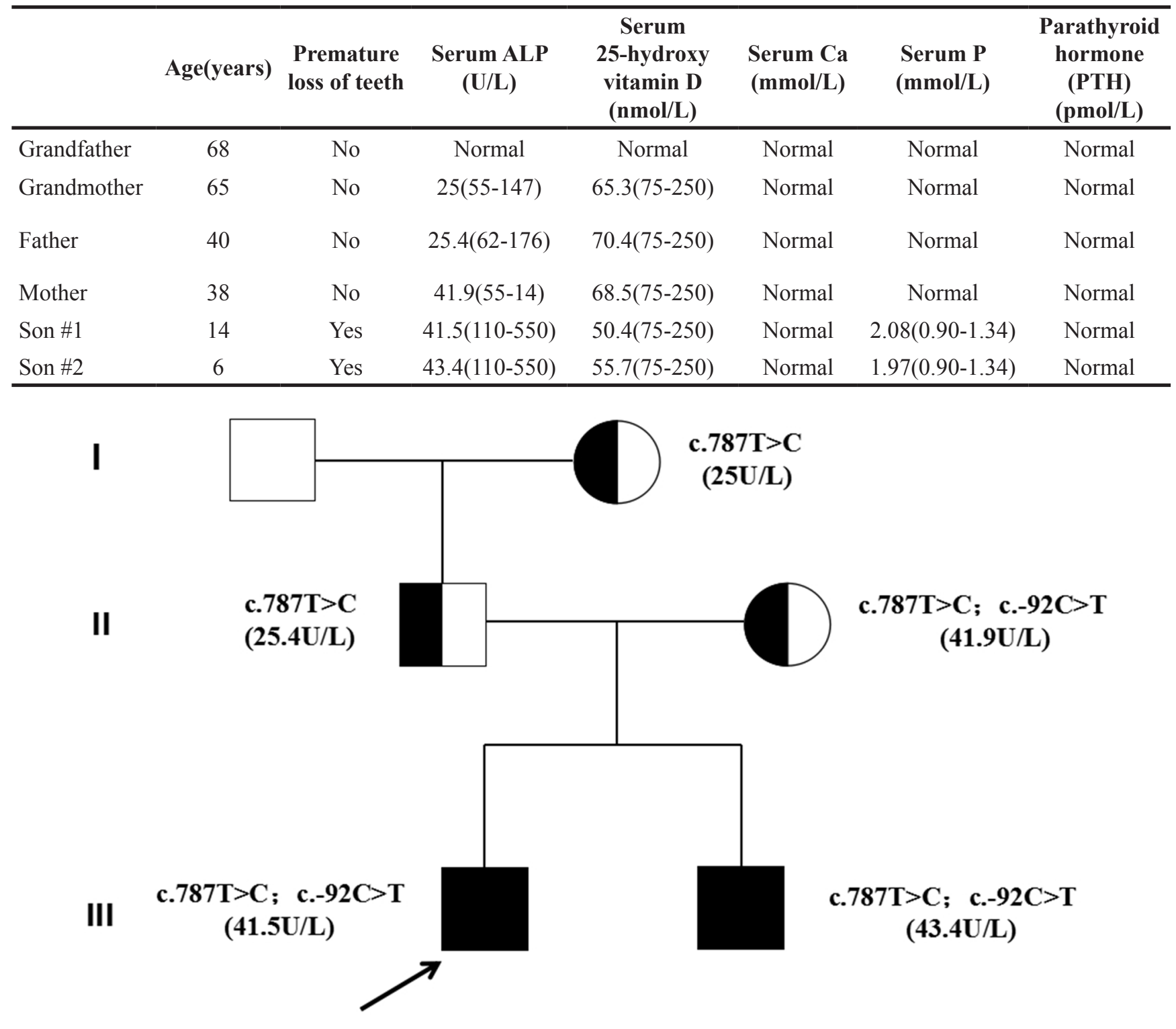

Male with no symptoms

Female with serum ALP disorders exhibited no other clinical symptoms

Male with serum ALP disorders exhibited no other clinical symptoms

Male with serum ALP disorders and premature loss of primary teeth

Proband

Figure 4: Kindred pedigree. Three generations depicting which women or men carry the TNSALP mutation. 
Table 2: Mutation analysis of the pedigree in this study

\begin{tabular}{|c|c|c|c|c|c|c|c|c|c|c|c|c|}
\hline & Exon 1 & Exon 2 & Exon 3 & Exon 4 & Exon 5 & Exon 6 & Exon 7 & Exon 8 & Exon 9 & Exon 10 & Exon 11 & Exon 12 \\
\hline GF & wt & wt & wt & wt & SNP & wt & wt & wt & wt & wt & wt & SNP \\
\hline GM & & wt & & & & & SNP & & SNP & & & \\
\hline Father & wt & wt & wt & wt & SNP & wt & SNP & wt & SNP & wt & wt & SNP \\
\hline Mother & & mut & & & & & SNP & & SNP & & & \\
\hline Son \#1 & wt & mut & wt & wt & SNP & wt & SNP & wt & SNP & wt & wt & SNP \\
\hline Son \#2 & wt & mut & wt & wt & SNP & wt & SNP & wt & SNP & wt & wt & SNP \\
\hline $\begin{array}{l}\text { Genomic } \\
\text { location }\end{array}$ & & $\begin{array}{c}\text { Chr1: } \\
21553989 \\
\text { C-> G }\end{array}$ & & & $\begin{array}{c}\text { Chr1: } \\
21563142 \\
\text { T->C }\end{array}$ & & $\begin{array}{c}\text { Chr1: } \\
21568242 \\
\text { T->C }\end{array}$ & & $\begin{array}{c}\text { Chr1: } \\
21573678 \\
\text { A->G }\end{array}$ & & & $\begin{array}{c}\text { Chr1: } \\
21577774 \\
\text { A->G }\end{array}$ \\
\hline $\begin{array}{l}\text { DNA } \\
\text { location }\end{array}$ & & c.C- $-92>\mathrm{G}$ & & & c.T330C & & c.T787C & & c.A876G & & & c. $A 1701>G$ \\
\hline $\begin{array}{l}\text { Protein } \\
\text { location }\end{array}$ & & 5'UTR & & & $\begin{array}{l}\text { Non- } \\
\text { sense }\end{array}$ & & p.Y263H & & $\begin{array}{l}\text { Non- } \\
\text { sense }\end{array}$ & & & 3'UTR \\
\hline
\end{tabular}

Wt: wild type; mut: mutation; SNP: the variants can be find in the SNP database; GF: grandfather; GM: grandmother.

a glycosylphosphatidylinositol(GPI) ancchors attached to its carboxyl terminus $[11,19]$. The enzyme is activated as a homodimer rather than a monomer [9]. Because of the structural properties of the TNSALP, some ALPL gene mutations that affect protein structures may exhibit dominant negative effects in heterozygotes, leading to mild HPP phenotypes. These mutations exhibited dominant negative effect by inhibiting the enzymatic activity of the wild-type (WT) in heterodimers [20, 21] or mutated protein sequestrate the WT protein into the cell and prevents it from being transported to the membrane [20]. The mutant carriers may not show the disease clearly and promote the variability of the clinical phenotype of HPP. Therefore, we suggest that SNP c.787T $>$ C may show a dominant negative effect, leading to a variable clinical phenotype of the family.

A novel mutation, c.-92C $>$ T, located at 5'UTR was identified in the brothers and their mother in this study.
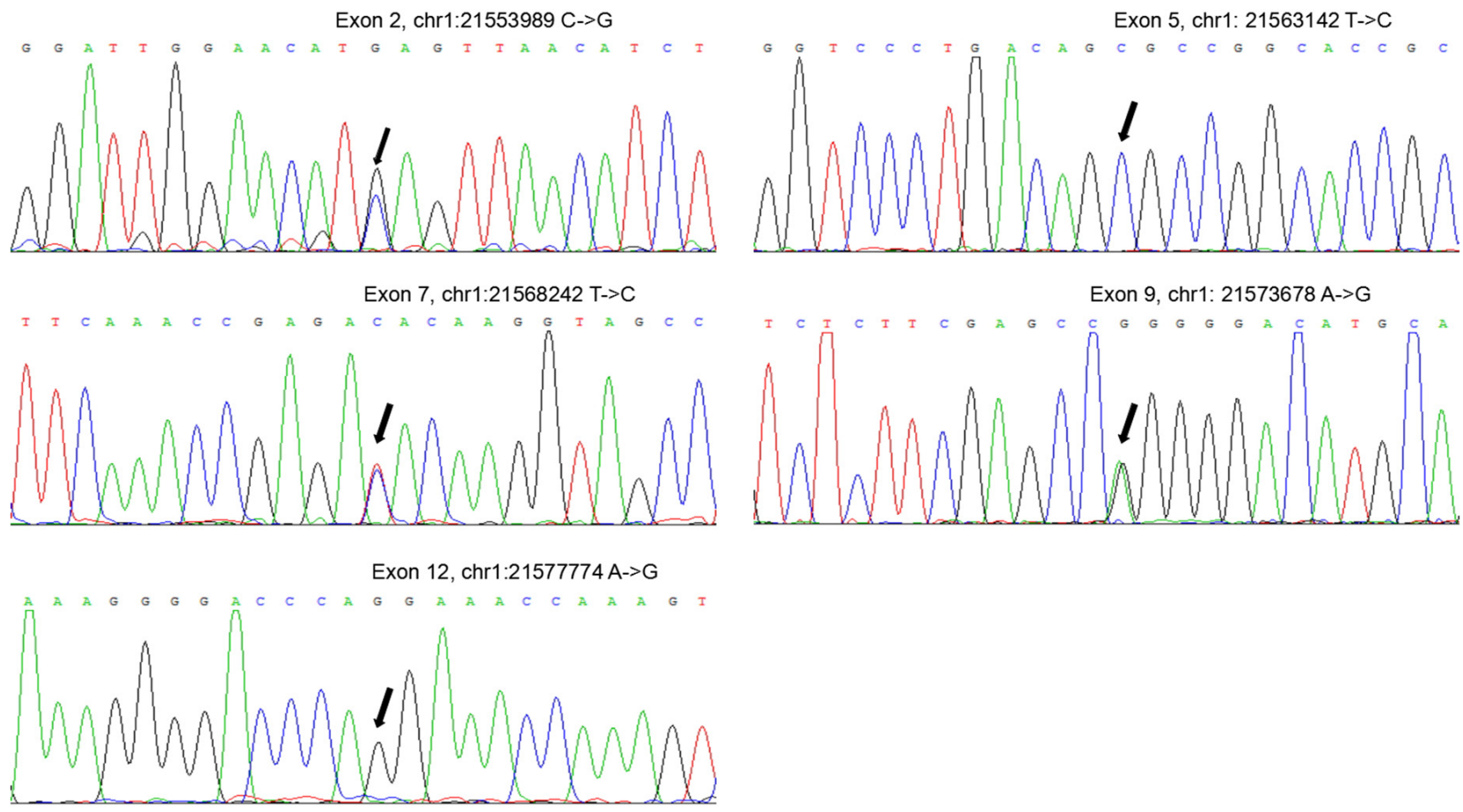

Figure 5: Genetic analysis of the HPP family. Sequencing chromatographs of genomic DNA from the proband; the arrow indicates the position of the mutation. 
Table 3: Primer sequence of ALPL gene exons

\begin{tabular}{|c|c|c|}
\hline Exon & Primer sequence $\left(5^{\prime}->3^{\prime}\right)$ & Chromosome position (hg38) \\
\hline 1 & $\begin{array}{l}\text { F: AAGCCAGATATGTTGACAGA } \\
\text { R: GCCATTAAAGTTCAACCA }\end{array}$ & Chr1: 21508967-21509622 \\
\hline 2 & $\begin{array}{l}\text { F: CTGGTCTGTAATAGGTGCTCAC } \\
\text { R: GTTTCCTGCTCTGAACACTGT }\end{array}$ & Chr1: $21553856-21554276$ \\
\hline $3-4$ & $\begin{array}{l}\text { F: CTCCAAGTTCAGGCATTCCAG } \\
\text { R: CGCAAGCAGGTACAGTGATG }\end{array}$ & Chr1: 21560516- 21561395 \\
\hline 5 & $\begin{array}{l}\text { F: AGGAAGCAGGCAGCTAGGTAGT } \\
\text { R: ATCTCAAGTGGACTGTGGCTCTG }\end{array}$ & Chr1: 21562927- 21563747 \\
\hline $5-6$ & $\begin{array}{l}\text { F: TAGGTAGTCCTGTGGCTCTGG } \\
\text { R: CCTGGATGCCTGGTTCTTGG }\end{array}$ & Chr1: $21562941-21564460$ \\
\hline 7 & $\begin{array}{l}\text { F: GGAAGCCAAGTAAGGTAAGTTATC } \\
\text { R: CTCAATGTCCACGCAGGTTAT }\end{array}$ & Chr1: $21567849-21568504$ \\
\hline 8 & $\begin{array}{l}\text { F: CATTAGAACATCACCTCCACCAG } \\
\text { R: GCCTAATTCCAGGAACCAGAAC }\end{array}$ & Chr1: $21570028-21570548$ \\
\hline 9 & $\begin{array}{l}\text { F: GTCACAGCCTCTCAGCATCC } \\
\text { R: CTCCTTCCACAACCTATTCTCCT }\end{array}$ & Chr1: 21573621- 21573941 \\
\hline $10-11$ & $\begin{array}{l}\text { F: CAGGTTGAATGGCTGCGTAA } \\
\text { R: CTGCTAGATTGTAGAAGGCGATT }\end{array}$ & Chr1: 21575556- 21576834 \\
\hline 12 & $\begin{array}{l}\text { F: CAGGCTCAGGTTCAAATCCC } \\
\text { R: AATGTTCCACGGAGGCTTCA }\end{array}$ & Chr1: 21577207- 21578001 \\
\hline
\end{tabular}

However, the clinical symptoms and signs of odontoHPP is special in affected individuals with c.-92C $>$ T mutation of this family, the brothers' serum ALP is lower than normal and exhibited significant premature loss of primary teeth, but their mother with below normal serum ALP level exhibited no other clinical symptoms related to HPP. Although the mother show no typical clinical manifestations of odonto-HPP (tooth loss), these results suggest that the heterozygosity of c. $-92 \mathrm{C}>\mathrm{T}$ may be associated with clinical symptoms in this family, but the disease is expressed at least in the mother. And we propose that the proband and his younger brother feature an c.-92C $>\mathrm{T}$ missense mutation of maternal inheritance in the regulatory sequence, which does not change the amino acid sequence but may promote the proband and his brother to show more aggressive dental phenotypes.

In conclusion, we identified the SNP c.787T $>C$ in the ALPL gene in a Chinese family with hypophosphatasia. This SNP may interfere with ALP activity, leading to a decrease in serum ALP levels. In addition to this SNP, the novel mutation c.-92C $>$ T located at 5'UTR may lead to more serious dental phenotype with the SNP c.787T $>$ C (p.Y263H). Our findings will further improve the knowledge of the relationship between regulatory sequence and phenotype, and have benefits to preimplantation genetic diagnosis and prenatal diagnosis. Further study will assess the effect of 5'UTR mutations on protein function.

\section{MATERIALS AND METHODS}

\section{Patients}

Two Chinese brothers, aged 6 and 14 years, were presented with premature exfoliation of primary teeth during early childhood life. Otherwise, they reported good health without evidence of bone disease. Their parents were asymptomatic and non-consanguineous.

The 14-year-old male proband due to early loss of primary teeth, was referred to our hospital in June 2014. He began to lose his teeth at the age of 2 , and lost all his teeth when he was 5 years old. However, after suffering a period of agomphosis malformation, his permanent teeth gradually began to erupt around 8 years old, and so far 26 permanent teeth have appeared. Moreover, the proband had no evidence of bone manifestations. The proband's younger brother, a 6-year-old boy, also appeared premature loss of primary teeth, so far has lost 12 primary teeth. The most frequent lost teeth are the incisors. Moreover, the little boy exhibited slight short stature and pectus excavatum.

In order to study the possibility of suffering from HPP, two boys conducted a further examination. The alveolar bone, pulp cavity, root and root absorbance were performed by panoramic X-ray examination. The bone mineral density (BMD) was measured by 
the quantitative ultrasonography. The X-ray of knee was performed to detect bone growth and pathological changes. The next laboratory tests included serum ALP, $\mathrm{Ca}, \mathrm{P}, 25$-hydroxyvitamin D, parathyroid hormone (PTH), erythrocyte sedimentation rate (ESR) and microelement.

\section{Family studies}

Subsequently, the pedigree of their family was investigated for HPP. Laboratory tests included serum total ALP activity, electrolyte and 25-hydroxy vitamin D of the two boys' parents and grandparents. None of them reported history of premature loss of primary teeth, fractures, weakness, skeletal pain, or growth retardation.

\section{Mutation studies}

Blood samples of family members were collected under Institutional Review Board-approved protocols, and written informed consent was obtained in accordance with the Declaration of Helsinki. Briefly, total RNA was isolated and extracted from peripheral blood cells using Trizol reagent (Invitrogen, CA, USA). One microgram of total RNA was subjected to reverse transcription with the random hexamers. Polymerase chain reaction (PCR) was then performed using cDNA as the template with the indicated primer pairs. The PCR products were then purified and sequenced directly (ABI 3730; Applied Biosystems). Primer sequence of ALPL gene exons was shown in Table 3.

\section{Author contributions}

Tang Liu and Yewei Wang conceived and designed the study. Jia Wan, Li Zhang, Tang Liu and Yewei Wang performed the experiments. Jia Wan, Li Zhang, Tang Liu and Yewei Wang wrote the manuscript. Jia Wan, Li Zhang, Tang Liu and Yewei Wang analyzed the data. All authors read and approved the final manuscript.

\section{ACKNOWLEDGMENTS}

This work was supported by the National Natural Science Foundation of China (Grant No. 81672176).

\section{CONFLICTS OF INTEREST}

The authors declare that they have no competing interests.

\section{REFERENCES}

1. Mornet E. Hypophosphatasia. Orphanet J Rare Dis. 2007; 2: 40 .

2. Bianchi ML. Hypophosphatasia: an overview of the disease and its treatment. Osteoporos Int. 2015; 26: 2743-2757. doi: 10.1007/s00198-015-3272-1.
3. Hu JC, Simmer JP. Developmental biology and genetics of dental malformations. Orthod Craniofac Res. 2007; 10: 45-52.

4. Reibel A, Manière MC, Clauss F, Droz D, Alembik Y, Mornet E, Bloch-Zupan A. Orodental phenotype and genotype findings in all subtypes of hypophosphatasia. Orphanet J Rare Dis. 2009; 4: 6. doi: 10.1186/1750-1172-4-6.

5. Weiss MJ, Ray K, Henthorn PS, Lamb B, Kadesch T, Harris H. Structure of the human liver/bone/kidney alkaline phosphatase gene. J Biol Chem. 1988; 263: 12002-12010.

6. Smith M, Weiss MJ, Griffin CA, Murray JC, Buetow KH, Emanuel BS, Henthorn PS, Harris H. Regional assignment of the gene for human liver/bone/kidney alkaline phosphatase to chromosome 1p36.1-p34. Genomics. 1988; 2: 139-143.

7. Whyte MP. Hypophosphatasia and the role of alkaline phosphatase in skeletal mineralization. Endocr Rev. 1994; 15: 439-461.

8. Orimo H. The mechanism of mineralization and the role of alkaline phosphatase in health and disease. J Nippon Med Sch. 2010; 77: 4-12.

9. Martins L, Rodrigues TL, Ribeiro MM, Saito MT, Giorgetti AP, Casati MZ, Sallum EA, Foster BL, Somerman MJ, Nociti FH Jr. Novel ALPL genetic alteration associated with an odontohypophosphatasia phenotype. Bone. 2013; 56: 390-397. doi: 10.1016/j.bone.2013.06.010.

10. Olsson A, Matsson L, Blomquist HK, Larsson A, Sjödin B. Hypophosphatasia affecting the permanent dentition. J Oral Pathol Med. 1996; 25: 343-347.

11. Herasse M, Spentchian M, Taillandier A, Keppler-Noreuil K, Fliorito AN, Bergoffen J, Wallerstein R, Muti C, SimonBouy B, Mornet E. Molecular study of three cases of odontohypophosphatasia resulting from heterozygosity for mutations in the tissue non-specific alkaline phosphatase gene. J Med Genet. 2003; 40: 605-609.

12. Wang ZY, Zhang K, Zheng GS, Qiao W, Su YX. Current concepts in odontohypophosphatasia form of hypophosphatasia and report of two cases. BMC Oral Health. 2016; 16: 70. doi: 10.1186/s12903-016-0266-0.

13. Silvent J, Gasse B, Mornet E, Sire JY. Molecular evolution of the tissue-nonspecific alkaline phosphatase allows prediction and validation of missense mutations responsible for hypophosphatasia. J Biol Chem. 2014; 289: 2416824179. doi: 10.1074/jbc.M114.576843.

14. Guañabens N, Mumm S, Möller I, González-Roca E, Peris P, Demertzis JL, Whyte MP. Calcific periarthritis as the only clinical manifestation of hypophosphatasia in middle-aged sisters. J Bone Miner Res. 2014; 29: 929-934. doi: 10.1002/ jbmr.2110.

15. Millán JL, Plotkin H. Hypophosphatasia - pathophysiology and treatment. Actual osteol. 2012; 8: 164-182.

16. Goseki-Sone M, Sogabe N, Fukushi-Irie M, Mizoi L, Orimo H, Suzuki T, Nakamura H, Orimo H, Hosoi T. Functional 
analysis of the single nucleotide polymorphism $(787 \mathrm{~T}>\mathrm{C})$ in the tissue-nonspecific alkaline phosphatase gene associated with BMD. J Bone Miner Res. 2005; 20: 773-782.

17. Sogabe N, Oda K, Nakamura H, Orimo H, Watanabe H, Hosoi T, Goseki-Sone M. Molecular effects of the tissuenonspecific alkaline phosphatase gene polymorphism (787T $>$ C) associated with bone mineral density. Biomed Res. 2008; 29: 213-219.

18. Fauvert D, Brun-Heath I, Lia-Baldini AS, Bellazi L, Taillandier A, Serre JL, de Mazancourt P, Mornet E. Mild forms of hypophosphatasia mostly result from dominant negative effect of severe alleles or from compound heterozygosity for severe and moderate alleles. BMC Med Genet. 2009; 10: 51. doi: 10.1186/1471-2350-10-51.

19. Yang H, Wang L, Geng J, Yu T, Yao RE, Shen Y, Yin L, Ying D, Huang R, Zhou Y, Chen H, Liu L, Mo X, et al.
Characterization of six missense mutations in the tissuenonspecific alkaline phosphatase (TNSALP) gene in Chinese children with hypophosphatasia. Cell Physiol Biochem. 2013; 32: 635-644. doi: 10.1159/000354467.

20. Lia-Baldini AS, Brun-Heath I, Carrion C, Simon-Bouy B, Serre JL, Nunes ME, Mornet E. A new mechanism of dominance in hypophosphatasia: the mutated protein can disturb the cell localization of the wild-type protein. Hum Genet. 2008; 123: 429-432. doi: 10.1007/ s00439-008-0480-1.

21. Lia-Baldini AS, Muller F, Taillandier A, Gibrat JF, Mouchard M, Robin B, Simon-Bouy B, Serre JL, Aylsworth AS, Bieth E, Delanote S, Freisinger P, Hu JC, et al. A molecular approach to dominance in hypophosphatasia. Hum Genet. 2001; 109: 99-108. 